\title{
Lifestyle profile of elderly living with non-communicable disease in Bangkok and Surabaya
}

\author{
Ni Putu Wulan Purnama Sari ${ }^{1}$, Jintana Artsanthia ${ }^{2}$ \\ ${ }^{1}$ Faculty of Nursing, Widya Mandala Catholic University Surabaya, Indonesia \\ ${ }^{2}$ Faculty of Nursing, Saint Louis College, Bangkok, Thailand
}

\section{Article Info \\ Article history: \\ Received Sep 25, 2019 \\ Revised Nov 21, 2019 \\ Accepted Nov 29, 2019}

\section{Keyword:}

Diabetes Mellitus

Elderly

Hypertension

Lifestyle

Non-communicable disease

\begin{abstract}
Lifestyle is one of the underlying risk factor of non-communicable disease (NCD). Dietary habit and exercise pattern are two indicators of lifestyle. Elderly are prone to NCD due to increased age which being independent risk factor. This study aimed to analyze and compare the lifestyle profile of elderly living with NCD between Bangkok and Surabaya, in term of dietary habit and exercise pattern, and to determine the best predictor of sedentary lifestyle among this population. This cross-sectional study involved 100 and 96 elderly with HT and/or DM in communities of Bangkok and Surabaya respectively $(\mathrm{n}=196)$. Self-developed instrument was used in data collection $(\mathrm{r}=0.178-0.715$, Chronbach Alpha=0.644). Mann-Whitney U and regression tests were used in data analysis $(\alpha<0.05)$. There was a significant difference of lifestyle in elderly living with NCD between Bangkok and Surabaya $(\mathrm{p}=0.008)$, especially in term of eat variety food $(\mathrm{p}=0.002)$, oily food $(\mathrm{p}=0.015)$, and curry with coconut milk $(\mathrm{p}=0.026)$. Eat vegetable and fruit could not predict dietary habit in elderly living with NCD $(\mathrm{p}=0.064)$. Eat fermented food was came up as the best predictor of lifestyle $(\mathrm{p}=0.000)$. It was accounted for $52.1 \%$ variance in lifestyle score in this population.
\end{abstract}

Copyright @ 2019 Institute of Advanced Engineering and Science. All rights reserved.

Corresponding Author:

Ni Putu Wulan Purnama Sari,

Faculty of Nursing, Department of Palliative Nursing,

Widya Mandala Catholic University Surabaya, Indonesia,

Jl. Raya Kalisari Selatan 1, Pakuwon City, Surabaya, Indonesia.

Email: wulanpurnama@ukwms.ac.id

\section{INTRODUCTION}

Non-communicable disease (NCD) leads to substantial mortality and morbidity worldwide. In Asia Pacific region, the most common NCD are cardiovascular diseases (e.g. hypertension or HT), cancer, and diabetes mellitus (DM) due to the increasing loss of disability adjusted life years [1]. Elderly are prone to NCD due to biological changes related to increased age because the incidence of NCD needs long duration to happen due to slow disease progression [2]. Age is epidemiologically recognized as an independent risk for NCD, especially cardiovascular diseases [3-4].

In Indonesia, the amount of elderly people was around 24.9 million or $8.9 \%$ in 2013 , and it was estimated to be increased up to 29.8 million or $21.4 \%$ [5]. Morbidity rate of elderly in 2015 was $28.62 \%$, meaning there were 28 sick elderly every 100 elderly population, in which HT was the highest NCD found in Indonesian elderly [6]. In Thailand, elderly claimed $15.3 \%$ of total population in 2014, and nine NCDs were among the top ten conditions in the disease burden ranking [2]. In 2011, diseases of circulatory system and diseases of endocrine, nutritional, and metabolic were being the two of the top ten leading causes of hospital deaths by 68.8 and 13.8 per 100,000 Thai elderly populations respectively [7]. NCD killed almost 28 million people in which 13 million is premature deaths because it occurs before the age of 70 in low-and middle-income countries [8]. 
One of the underlying risk factor of NCD in Asia Pacific region is sedentary lifestyle, which consists of tobacco use, alcohol consumption, inadequate physical activity, and unhealthy diet [1]. In DM type 2 (80-90\% of cases), the pancreas still produce enough insulin (sometimes more than normal), but the body develops resistance due to various factors related to unhealthy lifestyle, such as lack of exercise and imbalance diet pattern [9, 10]. Asia Pacific region has some strategies to manage NCD, such as: dietary salt reduction, health education, psychological interventions, taxation \& bans on tobacco-related advertisements, implementing smoke-free zones, and surveillance by the World Health Organization (WHO) [1].

This study aimed to analyze and compare the lifestyle profile of elderly living with NCD, especially HT and/or DM, between Bangkok and Surabaya, and to determine the best predictor of sedentary lifestyle among this population. HT and DM are two risk factors of NCD, together with underweight, obesity, waist: hip ratio, and total:HDL cholesterol level. In this study, lifestyle is indicated by the dietary habit and exercise pattern. Dietary habit consist of the eating pattern of variety food, vegetable \& fruit, sweets, curry; oily, toast, and fermented food; and the drinking pattern of soda \& alcohol. Foods, diet, and nutritional status are associated with elevated blood pressure and cholesterol, and resistance to the action of insulin. Therefore, what we eat and our nutritional status can affect cardiovascular disease (CVD) and DM. By knowing this study result, it will be beneficial for developing certain intervention to modify the predictors which enabling lifestyle modification in elderly living with NCD.

\section{RESEARCH METHOD}

This cross-sectional study involved 196 elderly with DM and/or HT in communities in Surabaya and Bangkok. There were 96 and 100 cases compiled from Surabaya and Bangkok respectively. In Bangkok, there were five communities used as study sites. In Surabaya, there were three communities used as study sites, namely: RW V, VI, and VII in the district of Mojo. Sample distribution between Bangkok and Surabaya is presented in Table 1.

Table 1. Sample distribution

\begin{tabular}{cccc}
\hline Case & Bangkok & Surabaya & Total \\
\hline DM & 30 & 30 & 60 \\
HT & 35 & 33 & 68 \\
DM\&HT & 35 & 33 & 68 \\
Total & 100 & 96 & 196 \\
\hline
\end{tabular}

Sample was chose by criteria then totally included in the study (total sampling). Inclusion criteria consist of (1) elderly who are willing to participate in the study, and (2) consume medication from medical doctor to treat the disease. Demography questionnaire was made to collect the data of respondents' characteristic, such as: age, gender, education, occupation, income, and family background of HT or DM. Variable was lifestyle which consisted of dietary habit and exercise as sub-variables. Both were assessed by self-developed instrument. There were ten items in the questionnaire: item 1-7 asked about food to eat, item 8-9 asked about beverage to drink, and item 10 asked about exercise. Likert scale of 1 to 5 was used to differentiate individual response: 1=everyday, 2=5-6 days/week, 3=3-4 days/week, 4=1-2 days/week, and $5=$ not at all. This questionnaire was proved to be valid and reliable $(\mathrm{r}=0.178-0.715$, Cronbach Alpha=0.644), except for item 2 about eat vegetable and fruit $(r=0.133, p=0.064)$. We decided not to eliminate item 2 because it is essential to assess.

Eating vegetable and fruit could increase antioxidant level in our body, especially important for combating the reactive oxygen species (ROS) which plays important role in the development of HT and cancer. After doing test of data distribution, we found that all data were not normally distributed (all $\mathrm{p}<\alpha$ ), therefore Mann-Whitney $U$ test was used to analyze lifestyle differences between Bangkok and Surabaya $(\alpha<0.05)$. The result of linearity test showed that only four items $(1-4)$ which were linear to overall lifestyle score, therefore linear regression test was used to determine the best predictor of lifestyle in elderly living with NCD in both sites $(\alpha<0.05)$. As for item 5-10 which were not linear to overall lifestyle score, ordinal regression test was used to determine the best predictor of lifestyle in this population in both sites $(\alpha<0.05)$.

Ethical clearance was issued by Ethical Committee of Saint Louis College (SLC), Bangkok, Thailand (November, 2016), with certificate number: E.038/2559. There was no conflict of interest between authors and study funder regarding this study and publication. 


\section{RESULTS AND DISCUSSION}

In total, the study respondents composed of $15.82 \%$ male and $84.18 \%$ female. Age range was 60-78 years old. The educational background of sample in Bangkok was mostly primary school (53\%), while in Surabaya was mostly secondary school $(64.58 \%)$. The income of sample in Bangkok was mostly $43 \%$ at THB 2,000-6,000 per month (43\%), while in Surabaya was mostly less than IDR 800 thousand per month (53.13\%). In Bangkok, most respondents has relative who suffered from DM/HT (66\%), while in Surabaya no family background was reported (69.79\%). Table 2 presents the demography characteristic of study respondents.

Table 2. Demography characteristic

\begin{tabular}{|c|c|c|c|c|}
\hline \multirow{2}{*}{ Characteristic } & \multicolumn{2}{|c|}{ Bangkok (100) } & \multicolumn{2}{|c|}{ Surabaya (96) } \\
\hline & $\mathrm{n}$ & $\%$ & $\mathrm{n}$ & $\%$ \\
\hline \multicolumn{5}{|l|}{ 1. Sex } \\
\hline a. Male & 20 & 20 & 11 & 11.45 \\
\hline b. Female & 80 & 80 & 85 & 88.54 \\
\hline \multicolumn{5}{|l|}{ 2. Age (years old) } \\
\hline a. $60-69$ & 48 & 48 & 75 & 78.13 \\
\hline b. $>70$ & 52 & 52 & 21 & 21.87 \\
\hline \multicolumn{5}{|l|}{ 3. Education } \\
\hline a. Primary school & 53 & 53 & 25 & 26.04 \\
\hline b. Secondary school & 25 & 25 & 62 & 64.58 \\
\hline c. Bachelor degree & 8 & 8 & 9 & 9.38 \\
\hline d. No study & 14 & 14 & 0 & 0 \\
\hline \multicolumn{5}{|l|}{ 4. Occupation } \\
\hline a. Farmer & 1 & 1 & 0 & 0 \\
\hline b. Businessman & 10 & 10 & 12 & 12.50 \\
\hline c. Government officer & 2 & 2 & 1 & 1.04 \\
\hline d. Other (retire, housewife) & 87 & 87 & 83 & 86.46 \\
\hline \multicolumn{5}{|l|}{ 5. Monthly income } \\
\hline a. $\mathrm{THB}<2,000(\mathrm{IDR}<800,000)$ & 18 & 18 & 51 & 53.13 \\
\hline b. THB $2,000-6,000$ (IDR $800,000-2.4$ million) & 43 & 43 & 31 & 32.29 \\
\hline c. THB $6,000-10,000$ (IDR $2.41-4$ million) & 19 & 19 & 10 & 10.42 \\
\hline d. THB > 10,000 (IDR>4 million) & 20 & 20 & 4 & 4.17 \\
\hline \multicolumn{5}{|l|}{ 6. Family background of HT/DM } \\
\hline a. Yes & 66 & 66 & 29 & 30.21 \\
\hline b. No & 34 & 34 & 67 & 69.79 \\
\hline
\end{tabular}

Results of Mann-Whitney U test showed that there was a significant difference of lifestyle in elderly living with NCD between Bangkok and Surabaya $(p=0.008)$, especially in term of eat variety food $(p=0.002)$ [Surabayan elderly eat more variety of food than Thai elderly everyday], eat oily food $(\mathrm{p}=0.015)$, and eat curry with coconut milk ( $\mathrm{p}=0.026)$. Consumption of vegetable and fruit was averagely higher in Bangkok elderly, but it was not statistically significant $(\mathrm{p}=0.634)$. Surabayan elderly preferred curry and oily food more than Bangkok elderly, and these was statistically significant ( $\mathrm{p}=0.026$ and $\mathrm{p}=0.015$ respectively). Consumption of sweets, toast, and fermented food was averagely higher in Surabayan elderly, but it was not statistically significant $(\mathrm{p}=0.083, \mathrm{p}=0.745$, and $\mathrm{p}=0.974$ respectively). Regarding drinking habit, most respondents in both sites were not drinking soda and alcohol ( $\mathrm{p}=0.061$ and $\mathrm{p}=0.543$ respectively). Surabayan elderly have slightly higher frequency of exercise compared to Bangkok elderly, but it was not statistically significant $(\mathrm{p}=0.092)$. Table 3 presents the lifestyle comparison in elderly living with NCD between Bangkok and Surabaya.

Table 3. Frequency of lifestyle

\begin{tabular}{|c|c|c|c|c|c|c|c|c|c|c|c|c|c|}
\hline \multirow{2}{*}{ Item } & \multirow[t]{2}{*}{ Lifestyle } & \multicolumn{6}{|c|}{ Bangkok $(n=100)$} & \multicolumn{6}{|c|}{ Surabaya $(n=96)$} \\
\hline & & 1 & 2 & 3 & 4 & 5 & Mean & 1 & 2 & 3 & 4 & 5 & Mean \\
\hline 1. & Eat variety food & 26 & 36 & 21 & 11 & 6 & 2.35 & 49 & 22 & 13 & 10 & 2 & 1.90 \\
\hline 2. & Eat vegetable and fruit & 33 & 25 & 26 & 13 & 3 & 2.28 & 39 & 14 & 30 & 9 & 4 & 2.22 \\
\hline 3. & Eat sweet dessert or sweet taste & 11 & 8 & 27 & 44 & 10 & 3.34 & 27 & 5 & 23 & 27 & 14 & 2.96 \\
\hline 4. & Eat oily food by frying food & 3 & 19 & 36 & 36 & 6 & 3.23 & 22 & 20 & 21 & 22 & 11 & 2.79 \\
\hline 5. & Eat toast food & 2 & 8 & 25 & 46 & 19 & 3.72 & 14 & 14 & 5 & 38 & 25 & 3.48 \\
\hline 6. & Eat curry with coconut milk & 0 & 10 & 29 & 40 & 21 & 3.72 & 15 & 13 & 15 & 40 & 13 & 3.24 \\
\hline 7. & Eat fermented food & 4 & 5 & 11 & 43 & 37 & 4.04 & 16 & 10 & 2 & 22 & 46 & 3.75 \\
\hline 8. & Drink soda or Pepsi or Coke & 7 & 2 & 11 & 34 & 46 & 4.10 & 18 & 2 & 1 & 10 & 65 & 4.06 \\
\hline 9. & Drink alcohol & 6 & 2 & 10 & 8 & 74 & 4.42 & 16 & 2 & 0 & 0 & 78 & 4.27 \\
\hline \multirow[t]{2}{*}{10.} & Exercise, such as: walking, aerobic & 24 & 11 & 23 & 28 & 14 & 2.97 & 29 & 29 & 20 & 26 & 6 & 2.64 \\
\hline & Overall lifestyle (Mean \pm SD) & \multicolumn{6}{|c|}{$34.17 \pm 4.99$} & \multicolumn{6}{|c|}{$31.30 \pm 6.29$} \\
\hline
\end{tabular}

Int. J. Public Health Sci. Vol. 8, No. 4, Dec 2019: 432-440 
Results of linear regression test showed that eat vegetable and fruit could not predict lifestyle (dietary habit) in elderly living with NCD ( $\mathrm{p}=0.064)$. Results of linear and ordinal regression tests showed that among all determinants eat fermented food was came up as the best predictor of lifestyle in this population $(\mathrm{p}=0.000)$. Eat fermented food was accounted for $52.1 \%$ variance in lifestyle score. Table 4 explains the influence of each predictor of dietary habit and exercise pattern on lifestyle in elderly living with NCD in Bangkok and Surabaya communities.

Table 4. Predictors of lifestyle

\begin{tabular}{ccccc}
\hline No. & DETERMINANT & R SQUARE & \% OF INFLUENCE & SIG. \\
\hline 1 & Eat variety food & 0.032 & 3.2 & 0.012 \\
2 & Eat vegetable and fruit & 0.018 & - & 0.064 \\
3 & Eat sweet dessert or sweet taste & 0.367 & 36.7 & 0.000 \\
4 & Eat oily food by frying food & 0.317 & 31.7 & 0.000 \\
5 & Eat toast food & 0.283 & 28.3 & 0.000 \\
6 & Eat curry with coconut milk & 0.299 & 29.9 & 0.000 \\
7 & Eat fermented food & 0.521 & 52.1 & 0.000 \\
8 & Drink soda or Pepsi or Coke & 0.396 & 39.6 & 0.000 \\
9 & Drink alcohol & 0.329 & 32.9 & 0.000 \\
10 & Exercise, such as: walking, aerobic, etc. & 0.158 & 15.8 & 0.000 \\
\hline
\end{tabular}

Various NCDs share one or more lifestyle-related risk factors, such as: smoking, high blood pressure, hyperglycemia, dyslipidemia, obesity, physical inactivity, and poor nutrition [11]. In order to address the problem of poor nutrition, many countries have developed their own dietary guidelines to be implemented by all citizens in the country. The dietary guideline for Indonesian citizen was developed by the Ministry of Health in 1995 which consisted of 13 messages. An evaluation study towards Indonesian citizen since 2000 until 2010 showed that the dietary guidelines were not optimally implemented, and the lackings in the existed guidelines including: smoking, increased intakes of fruit and vegetables, limited intakes of salt and sugar, increased intakes of foods rich in zinc and calcium (besides iron), handwashing before food preparation and eating, and weight-monitoring [12]. In the other hand, the dietary guidelines for Thailand citizen was developed in 1996 but consisted of nine messages only, and in 1998 anothe/ $\mathrm{r}$ food guide model was established. There has been no formal evaluation on the impact of promotion of the Thai-food-based dietary guidelines, but some periodic testing of knowledge and practices have shown positive results [13].

The growing epidemic of chronic disease worldwide was related to dietary and lifestyle changes which occured due to industrialization, urbanization, economic development, and market globalization, impacting health and nutritional status of a population, especially in developing countries [14]. In developing countries, such as Thailand and Indonesia, malnutrition and over nutrition tend to coexist which undergo a rapid nutritional transition [15]. Urbanization might be challenges the achievement of conducive nutritional environment to healthy eating [16]. Results showed that Surabayan elderly eat more variety of food than Bangkok elderly every day and this differences was statistically significant $(\mathrm{p}=0.002)$. It is indicating that Bangkok elderly have poorer food intake pattern. Unhealthy dietary patterns are associated with metabolic changes and increased risk of NCD [17]. A study towards 246 adults in Brazil showed that poor or inadequate food intake pattern could lead to metabolic syndrome which induced atherosclerosis and coronary heart disease [18]. Both Thai and Indonesian people eat rice as their main source of energy, similar to India. Learning from a study in India towards 7,067 adults which showed that the eating pattern was different between rural and urban setting: rural people tend to consume a rice-based pattern characterized by low energy consumption and dietary diversity, while more educated urban people tend to consume rice-based pattern with high fruit consumption [19]. Table 1 showed that Bangkok elderly was better educated than Surabaya elderly, but there was no significant difference in fruit and vegetable consumption $(\mathrm{p}=0.634)$. Eat vegetable and fruit could not predict lifestyle (dietary habit) in elderly living with NCD in this population ( $\mathrm{p}=0.064)$.

Monthly income could influence food intake pattern and healthy eating index. A study towards 128 urban women in Malaysia showed that income was positively correlated with food variety and fruits consumption; income strata and eating out frequency were independently affected the healthy eating index [16]. Table 1 showed that Bangkok elderly averagely have higher income than Surabaya elderly, and most respondents were female in both sites. A qualitative study in Mexico showed that household financial constraints and reduced availability of healthy food options could limit women's ability to access and consume diets consistent with the promotion of good health [20]. Higher income enables the improved standard of living, expansion of food availability, and increased access to services, 
but the negative consequences is inappropriate dietary patterns, increased tobacco use, decreased physical activity, and a corresponding increase in diet-related chronic diseases, especially among poor people [14].

As income is higher in Bangkok elderly, it is possible that the food intake pattern changes from a diet based on staples toward one of a higher consumption of meat and processed foods, including refined sugar and vegetable oils [21]. Regarding consumption of vegetables \& fruits and processed food, especially the fermented food, results showed that there was no significant difference between Bangkok and Surabaya elderly ( $\mathrm{p}=0.634$ and $\mathrm{p}=0.974$ respectively). It is indicating that higher income cannot guarantee higher consumption of meat and processed foods, and lower income also cannot guarantee higher consumption of vegetables and fruits. Decreased vegetable intake was associated with eating out frequency and poor healthy eating index [16]. WHO recommends a daily consumption of at least 400 grams of fruits and vegetables for the prevention of chronic diseases [22]. A cohort study towards 3,704 adults ( $\mathrm{n}=653 \mathrm{DM}$ cases) showed that higher comsumption of combined fruit and vegetable, and more variety of consumption in fruit, vegetable, and combined fruit and vegetable was associated with a lower hazard of DM, while the quantity of vegetable intake only was negatively associated with DM [23].

Eating processed food, especially the fermented one, was found to be consumed averagely 1-2 days per-week by study respondents in both sites. Even eating fermented food was found to be the best predictor of lifestyle in this study context $\left(\mathrm{R}^{2}=0.521, \mathrm{p}=0.000\right)$. Fermented food is defined as food made by microbial organisms and enzymatic conversions of major and minor food components [24]. Basically, the process of fermentation is categorized by the microorganisms and primary metabolites involved, such as: alcohol and carbon dioxide (yeast), acetic acid (Acetobacter), lactic acid (lactic acid bacteria or LAB), propionic acid (Propionibacterium), ammonia and fatty acids (Bacillus, molds) [25]. Results of a meta-analysis towards 25 RCTs showed that there was no specific study aiming at finding the effect of eating fermented food on human health, but the strongest evidence showed that eating yogurt could be a risk factor of developing DM due to the increased bioavailability of insulinotropic amino acids, peptides, and bacterial biosynthesis of vitamin K2 [24]. A study in Canada towards 5,643 households showed that mostly Canadian consumed the ultra-processed food more than the WHO upper limits for fat, saturated fat, free sugars and Natrium density which in total more than the average energy density target of certain cancer organization which was unhealthy; but they consumed less fibre than recommended [26].

Results showed that consumption of sweets was averagely higher in Surabaya elderly compared to Bangkok, but it was not statistically significant $(\mathrm{p}=0.083)$. Most respondents consumed sweets averagely $1-2$ day per-week in both sites. Sugar consumption is linked to a rise in NCD, and its effects on the body can be similar to those of alcohol [27]. Consumption of sweets was related to gender. In this study, more female elderly participated than male in both sites; even though Surabaya had lower sample size than Bangkok, but more female elderly were found. In different population, a study towards 723 adolescents (350 boys and 373 girls) in Iraq showed that boys and girls have a very different eating habits and it was significant. Boys tend to eat more fast food, sugar sweetened and energy drinks than girls, but girls did less physical activity than boys [28]; both lifestyles are bad for our health and have a possible impact on NCD prevalence in the future. Another qualitative study towards 120 Uruguayan showed that sweet foods and chocolate were first food come to mind when talking about wellbeing in a food-related context which was strongly associated with physical health; participants expected effects of foods on wellbeing were mainly related to NCD, such as HT, CVD, and hypercholesterolemia [29].

Still related to sweets and sugar consumption, results showed that most respondents in both sites were not drinking soda frequently ( $\mathrm{p}=0.061$ ), mostly was choosing "not at all". Soda is considered as sugar sweetened beverage related to obesity. Even in some countries the government implements tax policy and purchasing age limits towards soda and other sugar sweetened beverages (SSB) in order to prevent obesity and NCD, such as USA, Mexico, Brazil, France, Ecuador, India, Peru, and South Africa. Results of a meta-analysis showed that a tax on SSB could reduce the obesity rate [30], and results of a systematic review showed that the net energy intake will sufficiently decrease by taxing SSB in order to prevent the increase prevalence of obesity in the population [31]. Specifically in India, the consumption of sugar, salt, and fat in each household is consistently and significantly associated with overweight and obesity but inconsistently associated with the occurrence of NCD, especially HT and DM [32].

Results showed that consumption of toasted food was averagely higher in Surabaya elderly compared to Bangkok, but it was not statistically significant $(\mathrm{p}=0.745)$. Most respondents consumed toast averagely 1-2 day per-week in both sites. Regarding the effect of regularly consuming toasted food towards the incidence of NCD, there was no specific study provided online. A study towards ten healthy subjects showed that toasted bread compared to fresh commercial white bread had lower IAUC values (glycemic index) [33], which is better to be consumed by DM patients. The toasting process, which is a non-enzymatic browning reactions, could generate antioxidant activity similar to the baking process [34]. Antioxidants are suggested to beneficially interfere with diseases-related oxidative stress, such as CVD [35]. 
A study towards Tehranian adults showed that food group of refined grains, all white breads, pasta, white flour, rice, rice flour, starch, sweet breads, toasted bread, and toasted flour belongs to healthful diet pattern (HDP), and the decreased adherence towards HDP could contribute to obesity [36]. Obesity is clearly driving a parallel epidemic of associated NCD in all age-groups, including type 2 DM, hyperlipidemia, HT, atherosclerosis, obstructive sleep apnea, and liver dysfunction [37]. A comparative study between South Asians and White Caucasians showed that South Asians are at higher risk for NCD due to rapid nutrition and lifestyle transitions, especially type $2 \mathrm{DM}$ and CHD, as well as obesity and obesity-related NCD [38].

We found a significant difference in eating oily food between study sites $(\mathrm{p}=0.015)$. Most Bangkok elderly rarely eat oily food (1-2 days per-week), but most Surabaya elderly eat oily food almost everyday because of frying process by using coconut oil. Oily food contains high saturated fat content which is generally considered as unhealthy by most people, especially for heart health. A study towards 2,222 decedents in north India showed that food with high w-6/w-3 ratio of fatty acids were positively associated with deaths due to NCDs [39]. The saturated fat contained in coconut oil is the 12-carbon variety, called lauric acid, which contains many antioxidants and other substances; its effect on health can't be predicted just by the changes in LDL and HDL [40]. So other than negative effect, coconut oil also has some benefits for health. Coconut oil contains unusually high amount of medium-chain triglycerides (MCTs) and $2.6 \%$ fewer calories than other fat, beneficial for increasing HDL cholesterol, controlling blood sugar, preventing liver disease, reducing asthma symptoms, and promoting weight loss [41].

There was a significant difference found between study sites in eating curry with coconut milk $(\mathrm{p}=0.026)$. Bangkok and Surabaya elderly mostly eat curry with coconut milk 1-2 day per-week. Coconut milk, a white and milky substance extracted from the flesh of mature coconuts, contains MCT which could stimulate weight loss, lower cholesterol, decrease metabolic syndrome, abdominal obesity, and inflammation; and improve exercise endurance [42]. Evidences showed that MCT could reduce body weight and waist size, balance out unstable gut microbiota, and the imbalance in this aspect may develop obesity [43]. A study towards overweight men found that consuming MCTs at breakfast led to reduced food intake later in the day [44]. Another study found that supplementation of coconut milk significantly reduced LDL cholesterol levels and increased HDL cholesterol levels [45]. Therefore it may be stated that intake of coconut milk is not a risk factor of vascular disease [46].

Results showed that most respondents in both sites were not drinking alcohol frequently $(\mathrm{p}=0.543)$, mostly was choosing "not at all". There is a strong link between alcohol and NCD, particularly cancer, CVD (HT, haemorrhagic stroke and atrial fibrillation), liver disease, pancreatitis, and DM [47]. Alcohol consumption, together with smoking, excess weight, and dietary factors have a great contribution to the global NCD burden, such as HT, DM, and hypercholesterolemia [48]. But, a study towards Chinese elderly in Shanghai showed that among 1,304 new cases of type 2 DM, moderate alcohol intake (1-3 drinks/day) was inversely related to risk of type 2 DM [49]. Therefore, alcohol consumption in certain tolerable amount is not harmful for health, but the hazardous alcohol intake is. Globally, the excess alcohol consumption causes almost 3.3 million deaths per-year (or $5.9 \%$ of all deaths), and $5.1 \%$ of the global disease burden is related to alcohol intake [50]. So, one of the five priority actions of NCD crisis globally is the reduction in hazardous alcohol intake, together with tobacco control (the most urgent and immediate priority), salt reduction, improved diets and physical activity, and essential drugs and technologies [51].

Surabaya elderly have slightly higher frequency of exercise compared to Bangkok elderly, but it was not statistically significant $(\mathrm{p}=0.092)$. A study towards 1,007 elderly in Augsburg showed that physical activity is inversely associated with multimorbidity specificly in elderly men, while elderly women did less physical activity and no significant result found in this group [52]. Another study towards Chinese elderly in Shanghai showed that among 1,304 new cases of type 2 DM, physical activity was inversely associated with type 2 DM risk, while total physical activity metabolic equivalent values (METs) had inverse negative dose-response relationships with type $2 \mathrm{DM}$, and regular participation in exercise or sports reduced type 2 DM risk [49]. In elderly, physical activity benefits them as the effective DM treatment, especially the moderate- to high-intensity exercises; while the resistive activities particularly benefits those with frailty and the vulnerable population [53]. Regarding HT, results of a systematic review showed that physical activity is good for HT prevention, but the optimal prescription remains difficult to be determined [54]. But, Ghadieh (2015) found that moderate intensity aerobic exercise was good for HT prevention and useful for managing stage $1 \mathrm{HT}$, while the dynamic resistance exercise was good for lowering blood pressure [55].

Bangkok and Surabaya's authority need to promote WHO guidelines of food intake in order to better prevent the occurrence of NCD, especially in elderly population. Government could make a policy aiming at reducing or banning the unhealthy-food-related advertisement in order to improve HDP, as well as continueing the public information campaigns beneficial for increasing the awareness of unhealthy eating. Brambila-Macias recommended that the government could make a policy targeting the market environment, 
such as fiscal measures and nutrient, food, and diet standards, which is more intrusive but may be more effective for promoting HDP [56].

\section{CONCLUSION}

There was a significant difference of lifestyle in elderly living with NCD between Bangkok and Surabaya, especially in term of eat variety food, oily food, and curry with coconut milk. Surabayan elderly eat more variety of food, preferred curry with coconut milk and oily food more than Bangkok elderly. Consumption of vegetable and fruit was averagely higher in Bangkok elderly, but eat vegetable and fruit could not predict dietary habit in elderly living with NCD. Consumption of sweets, toast, and fermented food was averagely higher in Surabaya elderly. Eat fermented food was came up as the best predictor of lifestyle in this population, and it was accounted for $52.1 \%$ variance in lifestyle score. Regarding drinking habit, most respondents in both sites were not drinking soda and alcohol. Surabaya elderly have slightly higher frequency of exercise compared to Bangkok elderly, but it was not statistically significant.

\section{ACKNOWLEDGEMENTS}

This study was funded by Widya Mandala Catholic University Surabaya (Grant number: 183a/WM01.5/N/2017) and Saint Louis College, Bangkok, Thailand. This publication is supported by Faculty of Nursing, Widya Mandala Catholic University Surabaya.

\section{REFERENCES}

[1] W-Y. Low, Y-K. Lee, A. L. Samy, "Non-communicable Diseases in the Asia-Pacific Region: Prevalence, Risk Factors and Community-based Prevention," International Journal of Occupational Medicine and Environmental Health, vol.28, no.1, pp. 20-26, 2015.

[2] N. P. W. P. Sari, J. Artsanthia, "Comparison of Blood Pressure and Blood Glucose Level among Elderly with Noncommunicable Disease," International Journal of Public Health Science, vol.8, no.2, pp. 105-113, 2019.

[3] J. Guralnik, R. Havlik, "Demographics," in M. H. Beers, R. Berkow, The Merck of Manual of Geriatrics, $3^{\text {rd }}$ Edition, pp. 26, 2001. New Jersey (USA): Merck \& Co Inc White House Station.

[4] A. V. Chobanian, G. L. Bakris, H. R. Black, W. C. Cushman, L. A. Green, J. L. Izzo, et al, "The Seventh Report of the Joint National Committee on Prevention, Detection, Evaluation and Treatment of High Blood Pressure: The JNC VII Report," JAMA, vol.289, no.19, pp. 2560-2572, 2003.

[5] Ministry of Health (MoH), Republic of Indonesia (RI), "Info Datin: Hypertension, Health Department, Republic of Indonesia, Jakarta (in Bahasa Indonesia),” 2015. Retrieved from: http://www.depkes.go.id/folder/view/01/structure-publikasi-pusdatin-info-datin.html

[6] Ministry of Health (MoH), Republic of Indonesia (RI), "Elderly Analysis of Indonesia (in Bahasa Indonesia)," 2017. Retrieved from: www.depkes.go.id/download.php?file=download/pusdatin/lansia

[7] Thailand-World Health Organization (WHO)-South East Asia Regional Office, "Thailand," 2015. Retrieved from: http://www.searo.who.int/entity/health_situation_trends/data/hsp/thailand_hsp.pdf

[8] World Health Organization (WHO), "Non-Communicable Diseases Progress Monitor 2015 (September 2015)," 2015. Geneva: WHO.

[9] M. C. Rendy, T. H. Margareth, "Nursing Care Plan of Medical Surgical Nursing and Internal Disease (in Bahasa Indonesia)," 2012. Yogyakarta: Nuha Medika.

[10] W. R. Utaminingsih, "Getting to Know Diabetes, Hypertension, Heart Disease, and Stroke for a Better Quality of Life (in Bahasa Indonesia),” 2009. Yogyakarta: Media Ilmu.

[11] R. Arena, M. Guazzi, L. Lianov, L. Whitsel, K. Berra, C. J. Lavie, L. Kaminsky, M. Williams, M-F. Hivert, N. C. Franklin, J. Myers, D. Dengel, D. M. Lloyd-Jones, F. J. Pinto, F. Cosentino, M. Halle, S. Gielen, P. Dendale, J. Niebauer, A. Pelliccia, P. Giannuzzi, U. Corra, M. F. Piepoli, G. Guthrie, D. Shurney, AHA Writing Group, ESC /EACPR Writing Group, ACPM Writing Group, "Healthy Lifestyle Interventions to Combat Noncommunicable Disease-A Novel Nonhierarchical Connectivity Model For Key Stakeholders: A Policy Statement From The American Heart Association, European Society of Cardiology, European Association for Cardiovascular Prevention and Rehabilitation, and American College of Preventive Medicine," European Heart Journal, vol.36, no.31, pp. 2097-2109, 2015

[12] A. A. Usfar, U. Fahmida, "Do Indonesians Follow Its Dietary Guidelines?: Evidence Related to Food Consumption, Healthy Lifestyle, and Nutritional Status Within the Period 2000-2010," Asia Pacific Journal of Clinical Nutrition, vol.20, no.3, pp. 484-494, 2011.

[13] P. P. Sirichakwal, K. Sranacharoenpong, K. Tontisirin, "Food Based Dietary Guidelines (FBDGs) Development and Promotion in Thailand," Asia Pacific Journal of Clinical Nutrition, vol.20, no.3, pp. 477-483, 2011.

[14] World Health Organization (WHO), "Diet Nutrition and Prevention of Chronic Diseases: Report of a Joint WHO/FAO Expert Consultation (Report No. 916)," 2003. Geneva: World Health Organization. Retrieved from: www.who.int/hpr/ 
[15] E. T. Kennedy, J. Ohls, S. Carlson, K. Fleming, "The Healthy Eating Index: Design and Applications,” J Am Diet Assoc., vol.95, pp. 1103-1108, 1995.

[16] T. Karupaiah, W. C. S. Swee, S. Y. Liew, B. K. Ng, K. Chinna, "Dietary Health Behaviors of Women Living in High Rise Dwellings: A Case Study of an Urban Community in Malaysia," Journal of Community Health, vol.38, no.1, pp. 163-171, 2013.

[17] F. A. Olatona, O. O. Onabanjo, R. N. Ugbaja, K. E. Nnoaham, D. A. Adelekan, "Dietary Habits and Metabolic Risk Factors for Non-communicable Diseases in a University Undergraduate Population," Journal of Health, Population, and Nutrition, vol.37, no.21, DOI: https://doi.org/10.1186/s41043-018-0152-2, 2018.

[18] K. F. Silva, A. Prata, D. F. da Cunha, "Frequency of Metabolic Syndrome and the Food Intake Patterns in Adults Living in a Rural Area of Brazil," Revista da Sociedade Brasileira de Medicina Tropical, vol.44, no.4, pp. 425429, 2011.

[19] E. J. M. Joy, R. Green, S. Agrawal, L. Aleksandrowicz, L. Bowen, S. Kinra, J. I. Macdiarmid, A. Haines, A. D. Dangour, "Dietary Patterns and Non-communicable Disease Risk in Indian Adults: Secondary Analysis of Indian Migration Study Data," Public Health Nutrition, vol.20, no.11, pp. 1963-1972, 2017.

[20] R. Kimoto, D. Ronquillo, M. C. Caamano, G. Martinez, L. Schubert, J. L. Rosado, Ol Garcia, K. Z. Long, "Food, Eating and Body Image in the Lives of Low Socioeconomic Status Rural Mexican Women Living in Queretaro State, Mexico," Health \& Place, vol.25, pp. 34-42, 2014.

[21] G. Cannon, "Diet-Related Chronic Diseases," In: R. Flores, Gillespie S (editors), "Vision for Food, Agriculture and the Environment: Health and Nutrition," Emerging and Remerging Issues in Developing Countries: Policy Briefs, pp. 16-17, 2001. Washington: International Food Policy Research Institute.

[22] World Health Organization (WHO), "Diet, Nutrition and the Prevention of Chronic Disease: Report of a Joint WHO/FAO Expert Consultation," 2002. Geneva: World Health Organization. Retrieved from: http://www.who.int/dietphysicalactivity/publications/trs916/download/en/ webcite

[23] A. J. Cooper, S. J. Sharp, M. A. H. Lentjes, R. N. Luben, K-T. Khaw, N. J. Wareham, N. G. Forouhi, “A Prospective Study of the Association Between Quantity and Variety of Fruit and Vegetable Intake and Incident Type 2 Diabetes," Diabetes Care, vol.35, no.6, pp. 1293-1300, 2012.

[24] D. Gille, A. Schmid, B. Walther, G. Vergeres, "Fermented Food and Non-communicable Chronic Diseases: A Review," Nutrients, vol.10, no.4, pp. 448, 2018.

[25] M. L. Marco, D. Heeney, S. Binda, C. J. Cifelli, P. D. Cotter, B. Foligne, M. Ganzle, R. Kort, G. Pasin, A. Pihlanto; et al., "Health Benefits of Fermented Foods: Microbiota and Beyond," Curr. Opin. Biotechnol., vol.44, pp. 94-102, 2016.

[26] J-C Moubarac, A. P. B. Martins, R. M. Claro, R. B. Levy, G. Cannon, C. A. Monteiro, "Consumption of Ultraprocessed Foods and Likely Impact on Human Health," Public Health Nutrition, vol.16, no.12, pp. 2240-2248, 2013.

[27] R. H. Lustig, L. A. Schmidt, C. D. Brindis, "The Toxic Truth About Sugar," Nature, vol.482, pp. 27-29, 2012.

[28] A. O. Musaiger, B. A. Al-Mufty, H. M. Al-Hazzaa, "Eating Habits, Inactivity, and Sedentary Behavior among Adolescents in Iraq: Sex Differences in the Hidden Risks of Noncommunicable Diseases," Food and Nutrition Bulletin, vol.35, no.1, pp. 12-19, 2014.

[29] G. Ares, L. De Saldamando, A. Gimenez, R. Deliza, "Food and Wellbeing: Towards A Consumer-based Approach," Appetite, vol.74, pp. 61-69, 2013.

[30] M. A. C. Escobar, J. L. Veerman, S. M. Tollman, M. Y. Bertram, K. J. Hofman, "Evidence That a Tax on Sugar Sweetened Beverages Reduces the Obesity Rate: A Meta-Analysis," BMC Public Health, vol.13, no.1072, DOI: https://doi.org/10.1186/1471-2458-13-1072, 2013.

[31] S. S. Nakhimovsky, A. B. Feigl, C. Avila, G. O'Sullivan, E. Macgregor-Skinner, M. Spranca, "Taxes on SugarSweetened Beverages to Reduce Overweight and Obesity in Middle-Income Countries: A Systematic Review," PLoS One, vol.11, no.9, pp. e0163358, 2016.

[32] N. K. Arora, R. Pillai, R. Dasgupta, P. R. Garg, "Whole-of-Society Monitoring Framework for Sugar, Salt, and Fat Consumption and Noncommunicable Diseases in India," Annals of The New York Academy of Sciences, vol.1331, pp. 157-173, DOI: 10.1111/nyas.12555, 2014.

[33] P. Burton, H. J. Lightowler, "The Impact of Freezing and Toasting on The Glycaemic Response of White Bread," European Journal of Clinical Nutrition, vol.62, pp. 594-599, 2008.

[34] J. S. Sidhu, Y. Kabir, F. G. Huffman, "Functional Foods from Cereal Grains," International Journal of Food Properties, vol.10, no.2, pp. 231-244, 2007.

[35] H. Mangge, K. Becker, D. Fuchs, J. M. Gostner, “Antioxidants, Inflammation and Cardiovascular Disease," World $J$ Cardiol, vol.6, no.6, pp. 462-477, 2014.

[36] F. Hosseini-Esfahani, S-A. Djazaieri, P. Mirmiran, Y. Mehrabi, F. Azizi, "Which Food Patterns are Predictors of Obesity in Tehranian Adults?," Journal of Nutrition Education and Behavior, vol.44, no.6, pp. 564-573, 2012.

[37] I. Kyrou, C. Tsigos, "Obesity in the Elderly Diabetic Patient: Is Weight Loss Beneficial? No," Diabetes Care, vol.32, no.2, pp. S403-S409, 2009

[38] A. Misra, L. Khurana, "Obesity-related Non-communicable Diseases: South Asians vs White Caucasians," International Journal of Obesity, vol.35, pp.167-187, 2011.

[39] J. Fedacko, V. Vargova, R. B. Singh, B. Anjum, T. Takahashi, M. Tongnuka, S. Dharwadkar, S. Singh, V. Singh, S. K. Kulshresth, F. De Meester, D. W. Wilson, "Association of High w-6/w-3 Fatty Acid Ratio Diet with Causes of Death Due to Noncommunicable Diseases Among Urban Decedents in North India," The Open Nutraceuticals Journal, vol.5, pp. 113-123, 2012. 
[40] W. C. Willett, “Ask The Doctor: Coconut Oil and Health: Is Coconut Oil Good for You?," 2018. Retrieved from: https://www.health.harvard.edu/staying-healthy/coconut-oil

[41] Y. Brazier, "How Many Calories Should I Eat a Day?," 2018. Retrieved from: https://www.medicalnewstoday.com/articles/245588.php

[42] Y. Wang, Z. Liu, Y. Han, J. Xu, W. Huang, Z. Li, "Medium Chain Triglycerides enhances exercise endurance through the increased mitochondrial biogenesis and metabolism," PloS One, vol.13, no.2, pp. e0191182, 2018.

[43] S. A. Rial, A. D. Karelis, K-F. Bergeron, C. Mounier, "Gut Microbiota and Metabolic Health: The Potential Beneficial Effects of a Medium Chain Triglyceride Diet in Obese Individuals," Nutrients, vol.8, no.5, pp. 281, 2016.

[44] M-P. St-Onge, B. Mayrsohn, M. O’Keeffe, H. R. Kissileff, A. R. Choudhury, B. Laferrere, "Impact of Medium and Long Chain Triglycerides Consumption on Appetite and Food Intake in Overweight Men," Eur J Clin Nutr., vol.68, no.10, pp. 1134-1140, 2014.

[45] R. A. I. Ekanayaka, N. K. Ekanayaka, B. Perera, P. G. S. M. De Silva, "Impact of a Traditional Dietary Supplement with Coconut Milk and Soya Milk on the Lipid Profile in Normal Free Living Subjects," J Nutr Metab, no.481068, DOI: $10.1155 / 2013 / 481068,2013$.

[46] S. Tuminah, M. Sihombing, "Frequent Coconut Milk Intake Increases The Risk of Vascular Disease in Adults," Universa Medicina, vol.34, no.2, pp. 149-158, 2015.

[47] C. D. Parry, J. Patra, J. Rehm, "Alcohol Consumption and Non-Communicable Diseases: Epidemiology and Policy Implications," Addiction, vol.106, no.10, pp. 1718-1724, 2011.

[48] S. S. Lim, T. Vos, A. D. Flaxman; et al., "A Comparative Risk Assessment of Burden of Disease and Injury Attributable to 67 Risk Factors and Risk Factor Clusters in 21 Regions, 1990-2010: A Systematic Analysis for The Global Burden of Disease Study 2010," Lancet, vol.380, pp. 2224-2260, 2012 [Erratum, Lancet, vol.381, pp. 1276, 2013].

[49] L. Shi, X-O. Shu, H. Li, H. Cai, Q. Liu, W. Zheng, Y-B. Xiang, R. Villegas, "Physical Activity, Smoking, and Alcohol Consumption in Association with Incidence of Type 2 Diabetes among Middle-Aged and Elderly Chinese Men," PLoS One, vol.8, no.11, pp. e77919, 2013.

[50] World Health Organization (WHO), "Global Status Report on Alcohol and Health 2014," 2014. Retrieved from: https://books.google.co.id/books?hl=en\&lr=\&id=HbQXDAAAQBAJ\&oi=fnd\&pg=PR2\&dq=alcohol+and+elderly +and+noncommunicable+disease \&ots=PbtFCjR4tK\&sig=Zphw46U6kqrqJZ0P29k9ivnM8E\&redir_esc $=\mathrm{y} \# \mathrm{v}=$ onepage\&q\&f=false

[51] R. Beaglehole, R. Bonita, R. Horton, C. Adams, G. Alleyne, P. Asaria, V. Baugh, H. Bekedam, N. Billo, S. Casswell, M. Cecchini, R. Colagiuri, S. Colagiuri, T. Collins, S. Ebrahim, M. Engelgau, G. Galea, T. Gaziano, R. Geneau, A. Haines, J. Hospedales, P. Jha, A. Keeling, S. Leeder, P. Lincoln, M. McKee, J. Mackay, R. Magnusson, R. Moodie, M. Mwatsama, S. Nishtar, B. Norrving, D. Patterson, P. Piot, J. Ralston, M. Rani, S. Reddy, F. Sassi, N. Sheron, D. Stuckler, I. Suh, J. Torode, C. Varghese, J. Watt (The Lancet NCD Action Group and the NCD Alliance), "Priority Actions for the Non-Communicable Disease Crisis," The Lancet, vol.377, no.9775, pp. 14381447, 2011.

[52] C. S. Autenrieth, I. Kirchberger, M. Heier, A-K. Zimmermann, A. Peters, A. Doring, B. Thorand, "Physical Activity is Inversely Associated with Multimorbidity in Elderly Men: Results from the KORA-Age Augsburg Study," Preventive Medicine, vol.57, no.1, pp. 17-19, 2013.

[53] J. H. Goedecke, E. O. Ojuka (eds), "Diabetes and Physical Activity," Med Sport Sci., vol.60, pp. 122-129, DOI: https://doi.org/10.1159/000357342, 2014.

[54] K. M. Diaz, D. Shimbo, "Physical Activity and the Prevention of Hypertension," Curr Hypertens Rep., vol.15, no.6, pp. 659-668, 2013.

[55] A. S. Ghadieh, "Evidence for Exercise Training in the Management of Hypertension in Adults," Can Fam Physician, vol.61, no.3, pp. 233-239, 2015.

[56] J. Brambila-Macias, B. Shankar, S. Capacci, M. Mazzocchi, F. J. A. Perez-Cueto, W. Verbeke, W. B. Trail, "Policy Interventions to Promote Healthy Eating: A Review of What Works, What Does Not, and What is Promising," Food and Nutrition Bulletin, vol.32, no.4, pp. 365-375, 2011. 